\title{
Aortocaval Fistula Presenting as Type 2 Acute Myocardial Infarction in a Patient with Severe Arteriopathy
}

\author{
Vivekanand Rajendran, Krishnaswamy Sundararajan, Alice Sawka \\ Department of Intensive Care, Royal Adelaide Hospital, Adelaide, South Australia 5000, Australia
}

\section{Abstract}

Aortocaval fistulas (ACFs) are rare with varied etiologies. Symptoms can be acute or delayed with predominant manifestations being high output cardiac failure. Acute coronary syndrome due to ACF has not been widely reported. We present a case of a 68 -year-old male who presented with signs and symptoms suggestive of acute coronary syndrome. This was confirmed by electrocardiogram changes and a rise in cardiac enzymes. A large abdominal aortic aneurysm was diagnosed initially by imaging without evidence of leak or rupture. A coronary angiogram showed only mild diffuse disease. On further reviewing, the computerized tomography imaging revealed an ACF. This was subsequently repaired with rapid improvement in his condition. Acute coronary syndrome is an unusual presentation of ACF with inadequately understood pathophysiological mechanisms. Prompt diagnosis and surgical management of this fistula are paramount to reduce mortality and morbidity.

Keywords: Abdominal aortic aneurysms, aortocaval fistula, myocardial infarction

\section{INTRODUCTION}

Aortocaval fistula (ACF) is a rare presentation of abdominal aortic aneurysms (AAAs). Most of them are spontaneous and fistulization occur commonly with inferior vena cava, iliac, or renal veins. A majority of those affected are males, in their seventh or eight decades of life.

Although the common presentations are that of high output cardiac failure or venous hypertension, we present a unique and uncommon case of ACF which presented as Type 2 acute myocardial infarction.

\section{Case Report}

A 68-year-old male presented to a country hospital with dizziness and diaphoresis. His past medical history included hypertension, hypercholesterolemia, an extensive smoking history, and mild thrombocytopenia of uncertain etiology. Electrocardiogram (ECG) showed widespread ST depression in leads II, III, aVF, and V3 to V6 with ST elevation in aVR [Figure 1]. Initial Troponin $\mathrm{T}$ value was $<40 \mathrm{ng} / \mathrm{L}$; however, repeat assay $6 \mathrm{~h}$ later was elevated at $1313 \mathrm{ng} / \mathrm{L}$. He was hypotensive at presentation, necessitating the use of vasoactive supports for transfer to our quaternary hospital

\begin{tabular}{|l|l|}
\hline \multicolumn{3}{c|}{ Access this article online } \\
\hline Quick Response Code: & Website: \\
& www.ijccm.org \\
& \\
\end{tabular}

for the management of presumed acute coronary syndrome complicated by cardiogenic shock.

Shortly following retrieval to our center, he reported acute back pain. He had a heart rate of $109 / \mathrm{min}$, oxygen saturations of $94 \%$ on 101 oxygen through a nonrebreather mask, blood pressure of $108 / 62 \mathrm{mmHg}$ on vasopressors, and his peripheries were cool. A focused ultrasound scan was suggestive of an AAA. Urgent computerized tomography (CT) scan with contrast subsequently confirmed the presence of an infrarenal AAA involving the iliac arteries, $95 \mathrm{~mm}$ at maximal axial diameter [Figure 2]. There was no evidence of leak. Bedside urgent echocardiography showed mild-to-moderate left ventricular (LV) dysfunction without any valve abnormalities.

An urgent coronary angiogram through right radial artery approach showed only mild diffuse disease in the mid-left anterior descending and right coronary arteries. The patient's clinical condition remained unchanged. At further review of the CT imaging, a fistulous communication between the inferior

Address for correspondence: Dr. Vivekanand Rajendran, Intensive Care Unit, 4G895, Level 4, ICU, Royal Adelaide Hospital, Port Road, Adelaide, South Australia 5000, Australia. E-mail: vicky.dr5098@gmail.com

This is an open access journal, and articles are distributed under the terms of the Creative Commons Attribution-NonCommercial-ShareAlike 4.0 License, which allows others to remix, tweak, and build upon the work non-commercially, as long as appropriate credit is given and the new creations are licensed under the identical terms.

For reprints contact: reprints@medknow.com

How to cite this article: Rajendran V, Sundararajan K, Sawka A. Aortocaval fistula presenting as Type 2 acute myocardial infarction in a patient with severe arteriopathy. Indian J Crit Care Med 2018;22:372-4. 
vena cava and the aneurysmal dilatation of the aorta at the L5 level was identified [Figure 3]. This prompted transfer to the operating theater for urgent open repair of the ACF.

Following midline laparotomy, a large nonruptured AAA was identified. The aorta was atheromatous and extensively calcified. The intraoperative course was complicated by major blood loss necessitating massive blood transfusion. The patient suffered hypovolemic arrest at the time of sac incision, with return of spontaneous circulation after five cycles of cardiopulmonary resuscitation.

Following successful repair of the ACF, the patient's hemodynamic status rapidly improved. Vasopressors were ceased by about $4 \mathrm{~h}$, and he was extubated $6 \mathrm{~h}$ later without evidence of neurological deficit related to the period of hypoperfusion. ECG changes reverted to normal [Figure 4]. The patient developed acute kidney injury; however, urine output was maintained. The patient was discharged from the Intensive Care Unit after a $24 \mathrm{~h}$ period of observation. He was discharged from the hospital 1 week later. Follow-up investigation showed resolution of the acute kidney injury [Table 1]. The premorbidly noted thrombocytopenia also resolved. Three months following his acute presentation,

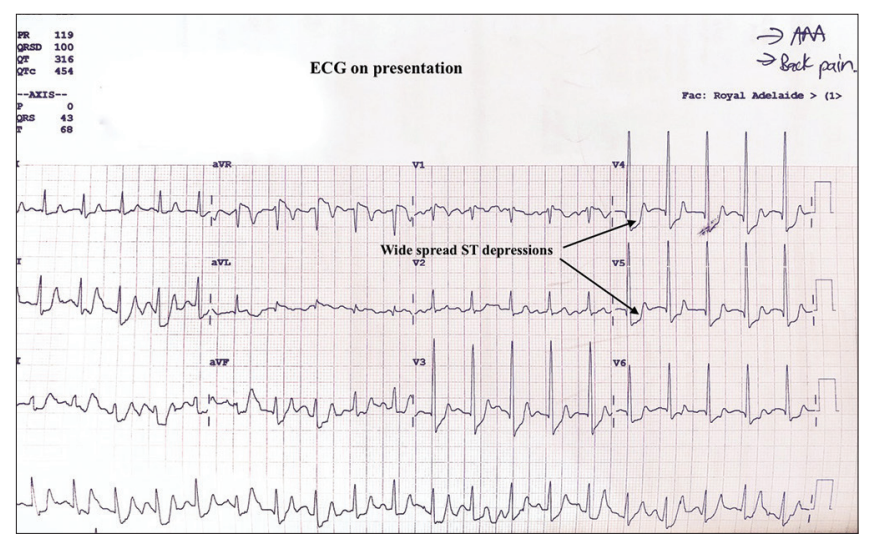

Figure 1: Electrocardiogram on presentation

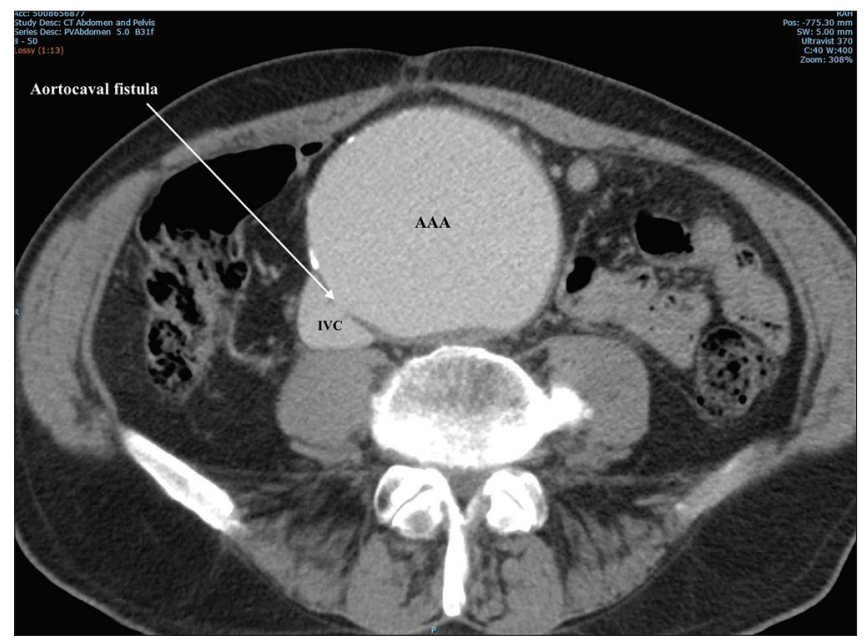

Figure 3: Axial section of computerized tomography abdomen showing the aortocaval fistula completion of the SF-30 questionnaire suggested a reduction in physical functioning to $70 \%$ of baseline.

\section{Discussion}

ACF is a widely reported but uncommon complication of AAA, with series suggesting an incidence between $0.2 \%$ and $10 \% .^{[1,2]}$ They are often diagnosed intraoperatively, ${ }^{[3]}$ where repair is associated with higher mortality compared with uncomplicated AAA. ${ }^{[4]}$ This is possibly due to the well-recognized association with intraoperative cardiac arrest. $^{[5]}$ While rupture of AAA is the most common cause of ACF $(80 \%)$, they may also occur following penetrating trauma $(15 \%)$ or complicate mycotic aneurysms, large vessel vasculitis, or develop iatrogenically, for example, as a complication of lumbar disc surgery. ${ }^{[6]}$

Classical clinical findings include pulsatile abdominal mass with an audible bruit, high output cardiac failure, and regional venous hypertension. ${ }^{[7-9]}$ Chest pain, lower extremity edema, priapism, rectal bleeding and hematuria, renal failure, intestinal angina, and intermittent claudication have also been reported as presenting features. ${ }^{[3]}$

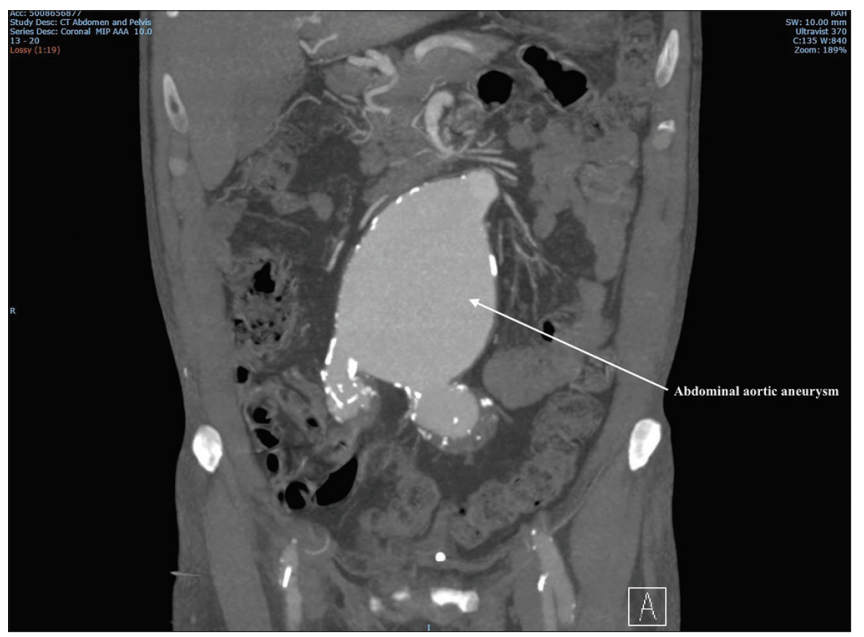

Figure 2: Coronal section of computerized tomography abdomen showing the abdominal aortic aneurysm

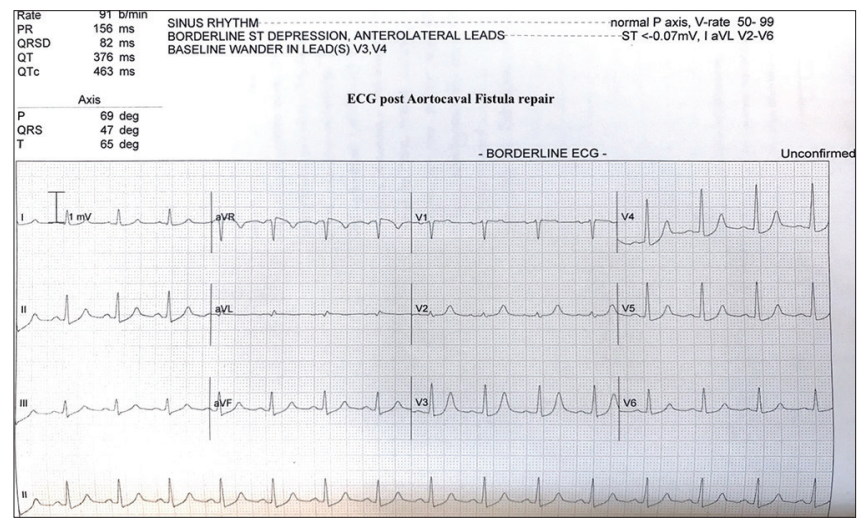

Figure 4: Electrocardiogram postfistula repair showing resolution of changes 


\begin{tabular}{|c|c|c|c|c|c|c|c|}
\hline & Premorbid & Presentation & 6 & $12 \mathrm{~h}$ (PEA arrest in OT) & $18 \mathrm{~h}$ & Day 2 & Day 7 \\
\hline Troponin T $(<30 \mathrm{ng} / \mathrm{L})$ & - & $<40$ & 1313 & 1439 & 2505 & - & - \\
\hline Creatinine $(50-120$ umol/L) & 105 & - & 232 & 231 & 220 & 169 & 74 \\
\hline
\end{tabular}

PEA: Pulseless electrical activity; OT: operation theatre

Acute coronary syndrome due to ACF is very rare; to the authors' knowledge, this is only the second case that has been described in the literature. Acute volume overload of the left ventricle could explain such a presentation. ${ }^{[10]}$ Animal studies have shown low systemic blood pressure and elevated LV end-diastolic pressure in the setting of ACF. ${ }^{[11]}$ The resulting shunt to the low-pressure caval system reduces coronary driving pressures during diastole, precipitating LV systolic and diastolic dysfunction. ${ }^{[1]}$ In other animal models, subendocardial fibrosis was seen in the infarcted and noninfarcted myocardium as a result of low coronary driving pressure. ${ }^{[12]}$ The presence of LV hypertrophy and mild coronary artery disease could aggravate the ischemic myocardial state precipitated by ACF.

Early diagnosis of ACF is challenging due to the wide scope of clinical presentations. Surgery, or endovascular treatment in selected cases, is the only chance of survival for these patients. $^{[13]}$

\section{Conclusion}

This case highlights the value of careful review of imaging where incongruous objective findings (such as the normal coronary angiogram) come into conflict with the clinical picture. We often rely on the maxim, "common things occur commonly." In this instance, the very common clinical entity of non-ST elevation myocardial infarction was precipitated by ACF through a very uncommon pathophysiological mechanism.

\section{Declaration of patient consent}

The authors certify that they have obtained all appropriate patient consent forms. In the form, the patient has given his consent for his images and other clinical information to be reported in the journal. The patient understands that name and initial will not be published, and due efforts will be made to conceal identity, but anonymity cannot be guaranteed.

\section{Financial support and sponsorship}

Nil.

\section{Conflicts of interest}

There are no conflicts of interest.

\section{References}

1. Schmidt R, Bruns C, Walter M, Erasmi H. Aorto-caval fistula - An uncommon complication of infrarenal aortic aneurysms. Thorac Cardiovasc Surg 1994;42:208-11.

2. Miani S, Giorgetti PL, Arpesani A, Giuffrida GF, Biasi GM, Ruberti U, et al. Spontaneous aorto-caval fistulas from ruptured abdominal aortic aneurysms. Eur J Vasc Surg 1994;8:36-40.

3. Bednarkiewicz $M$, Pretre $R$, Kalangos A, Khatchatourian G, Bruschweiler I, Faidutti B, et al. Aortocaval fistula associated with abdominal aortic aneurysm: A diagnostic challenge. Ann Vasc Surg 1997;11:464-6.

4. Ghilardi G, Scorza R, Bortolani E, De Monti M, Longhi F, Ruberti U, et al. Rupture of abdominal aortic aneurysms into the major abdominal veins. J Cardiovasc Surg (Torino) 1993;34:39-47.

5. Acroyd J, Burnand K. The aetiology of cardiac arrest in patients undergoing surgical closure of an acute aortocaval fistula. J Cardiovasc Surg 1983;24:667-8.

6. Abbadi AC, Deldime P, Van Espen D, Simon M, Rosoux P. The spontaneous aortocaval fistula: A complication of the abdominal aortic aneurysm. Case report and review of the literature. J Cardiovasc Surg (Torino) 1998;39:433-6.

7. Gilling-Smith GL, Mansfield AO. Spontaneous abdominal arteriovenous fistulae: Report of eight cases and review of the literature. Br J Surg 1991;78:421-5.

8. Taheri SA, Plonka AJ. Aortocaval fistula: Diagnosis and treatment: Case studies. Angiology 1986;37:314-8.

9. Lebon A, Agueznai M, Labombarda F. High-output heart failure resulting from chronic aortocaval fistula. Circulation 2013;127:527-8.

10. Garcia R, Diebold S. Simple rapid and effective method of producing aortocaval shunts in the rat. Cardiovasc Res 1990;24:430-2.

11. Mazzo FR, de Carvalho Frimm C, Moretti AI, Guido MC, Koike MK. Acute aortocaval fistula: Role of low perfusion pressure and subendocardial remodeling on left ventricular function. Int J Exp Pathol 2013;94:178-87.

12. de Carvalho Frimm C, Koike MK, Cúri M. Subendocardial fibrosis in remote myocardium results from reduction of coronary driving pressure during acute infarction in rats. Arq Bras Cardiol 2003;80:509-20.

13. Takazawa A, Sakahashi H, Toyama A. Surgical repair of a concealed aortocaval fistula associated with an abdominal aortic aneurysm: Report of two cases. Surg Today 2001;31:842-4. 